\title{
AÇÕES AFIRMATIVAS COMO MEIO DE DEFESA E INCLUSÃO SOCIAL
}

\author{
Tatiana da Silva Ferreira Nery \\ Universidade do Oeste Paulista
}

\section{RESUMO}

Este artigo aborda o conceito de Ações Afirmativas como meio de inclusão social das minorias, sua temporalidade e assim como os meios pelas quais elas estão sendo introduzidas no ordenamento brasileiro. Aborda também algumas das ações afirmativas mais conhecidas em face das mulheres, dos negros, dos homossexuais e dos portadores de deficiência trazendo um conceito amplo ligado a igualdade material, assim como as abordagens trazidas por alguns julgados do Supremo Tribunal Federal e Supremo Tribunal de Justiça.

Palavras-chave: Ações afirmativas, Minorias, Igualdade, Inclusão.

\section{INTRODUÇÃO}

Ações Afirmativas ou discriminações positivas consiste em políticas públicas ou programas privados criados temporariamente e desenvolvidos com a finalidade de reduzir as desigualdades decorrentes de discriminações ou hipossuficiência econômica ou física por meio da concessão de algum tipo de vantagem compensatória.

Elas estão ligadas ao principio da igualdade material, que esta consagrada na segunda dimensão dos direitos fundamentais, pois exige uma atuação positiva do Estado a fim de promover a igualização de desiguais por meio da concessão de direitos sociais. Percebe-se que elas não são apenas políticas públicas, mas também podem ser de iniciativa privada.

Uma das características das ações afirmativas é a sua temporalidade. Seus efeitos tendem a ir diminuindo e até cessar, quando se observar uma igualdade dos desiguais, ou seja, que as distorções sofridas por determinada classe venha a cessar. O texto da Convenção Internacional sobre Eliminação de Todas as Formas de Discriminação Racial (1968) relata que as medidas não deverão permanecer depois de alcançados os objetivos (art. 2ํ, §2ํ).

Artigo 2ㅇ - Os Estados-partes condenam a discriminação racial e comprometem-se a adotar, por todos os meios apropriados e sem dilações, uma política destinada a eliminar a discriminação racial em todas as suas formas e a encorajar a promoção de entendimento entre todas as raças, e para este fim:

2. Os Estados-partes tomarão, se as circunstâncias o exigirem, nos campos social, econômico, cultural e outros, medidas especiais e concretas para assegurar, como convier, o desenvolvimento ou a proteção de certos grupos raciais ou de indivíduos pertencentes a esses grupos, com o 
objetivo de garantir-lhes, em condições de igualdade, o pleno exercício dos direitos humanos e das liberdades fundamentais. Essas medidas não deverão, em caso algum, ter a finalidade de manter direitos desiguais ou distintos para os diversos grupos raciais, depois de alcançados os objetivos, em razão dos quais foram tomadas. (Convenção Internacional sobre Eliminação de Todas as Formas de Discriminação Racial-1968).

Entretanto ressalta-se que as ações afirmativas não são o único caminho para se igualar os desiguais, outras medidas positivas dos governos, a eliminação da discriminação e a conscientização da população também devem ser adotadas, para que a desigualdade seja superada.

\section{Ações afirmativas em favor da mulher}

Salienta-se que mesmo com os benefícios concedidos em 1940 pela CLT e com seus direitos ampliados pela Constituição Federal de 1988, ainda existe certo preconceito cultural com a sociedade feminina brasileira. Entretanto, atualmente as mulheres, através dos seus próprios esforços, vêm mudando esses fatos, ocupando posto que até antigamente, eram ocupadas por homem.

A Constituição Federal de 1988 trouxe muitas inovações, como por exemplo, a criação da Secretaria de Estado vinculada ao Ministério da Justiça, a Convenção de eliminação de todas as formas de discriminação contra as mulheres, além do empenho do Poder Executivo, Legislativo e Judiciário para a proteção dos direitos das mulheres. Houve também a multiplicação das delegacias das mulheres e a tipificação e incorporação do crime de assédio sexual no trabalho em 2001.

Em 2006, foi reconhecido pelo Conselho de Justiça (lei no 11.340), que os Tribunais dos Estados criassem Juizados Especiais de Violência Doméstica e Familiar contra a mulher. Outras ações afirmativas vêm no âmbito do direito do trabalho, reconhecendo e ampliando direitos, como no caso da ampliação do direito a licença maternidade, de 120 dias para 180 dias, e da estabilidade provisória da mulher gravida. Conforme decisão do STF:

O STF fixou entendimento no sentido de que as servidoras públicas e empregadas gestantes, inclusive as contratadas a título precário, independentemente do regime jurídico de trabalho, têm direito à licençamaternidade de 120 dias e à estabilidade provisória desde a confirmação da gravidez até cinco meses após o parto, nos termos do art. 70, XVIII, da CB e do art. 10, II, $b$, do ADCT. Precedentes." (RE 600.057-AgR, Rel. Min. Eros Grau, julgamento em 29-9-2009, Segunda Turma, DJE de 23-102009.) 
Salienta-se que outra conquista das mulheres foi à lei no 11.340/2006 conhecida como Maria da Penha em homenagem a mulher que depois de ter sido espancada e ficado paraplégica, formalizou uma denúncia à Comissão Interamericana de Direitos Humanos. Essa lei endureceu as penas dos agressores familiares, possibilitando a prisão em flagrante e medidas preventivas, além dos agressores não se beneficiarem com penas restritivas de direito. Destaca-se também a ajuda prestada pelas organizações sociais privadas e não governamental de mulheres, voltadas à defesa de sua cidadania.

\section{Ações afirmativas em favor dos homossexuais}

Historicamente os homossexuais são vitimas de vários preconceitos, são vitimas de agressão, tanto física como moral, verbal ou sexual. Ressalta-se que muitas destas violências são sofridas em seus próprios lares ou nas ruas. Álvaro R. S. Cruz cita um caso ocorrido no final da década de 1960, ficando conhecido como "Batalha de Stonewall", do qual foi reconhecido internacionalmente como "Dia Internacional do Orgulho Gay".

O bar Stonewall-Inn era um bar frequentado por homossexuais do final da década de 1960, em Nova York. Constantemente invadido pela policia por sua tolerância para com a homossexualidade de seus clientes, finalmente, no dia 28 de junho d 1969, travestis, gays e lésbicas reagiram contra a arremetida policial que procurava prender todos os clientes "suspeitos". Durante dois dias, os homossexuais reagiram a "violência policial" ao final deles, parcela significativa de toda a população estava ao lado dos mesmos. No terceiro dia, o bar foi reaberto e a policia finalmente os "deixou em paz" (2009, p. 199).

Ainda relata o autor que por coincidência o "Dia do Orgulho Gay" cai no falecimento de Judy Garland, ícone da comunidade gay, que no filme $\mathrm{O}$ magico de $\mathrm{Oz}$, sonhava com um mundo melhor. Em toda a histórica é nítida a participação de movimentos não governamentais que se organizam em favor desta minoria. No Brasil apesar de alguns avanços, como a decisão inédita, do STJ que reconheceu a possibilidade de habilitação de pessoas do mesmo sexo para o casamento civil no REsp 1.183.378, ainda há muitas episódios de preconceitos. O reconhecimento do INSS em relação aos direitos do parceiro foi obtido com um pouco de resistência por parte da Autarquia, porem hoje é algo pacifico. Atualmente, tem se um grande debate, uma vez que o atual Presidente da Comissão de Direitos Humanos da Câmara, Marcos Feliciano (PSC-SP) é acusado de ser homofóbico e racista. 
'Papai do Céu'. Entre os projetos de lei apresentados por Feliciano, há um que institui o programa "Papai do Céu na Escola" na rede pública de ensino e outro que pretende sustar a decisão do Supremo Tribunal Federal que reconheceu como entidade familiar a união entre pessoas do mesmo sexo. Ele propôs ainda um projeto de lei para punir quem sacrifica animais em rituais religiosos, prática adotada em algumas cerimônias do candomblé.

\section{Ações afirmativas em favor dos negros}

O Brasil ratificou a Convenção Internacional para a Eliminação de Todas as Formas de Discriminação Racial, entretanto ao que se pese, o pais está bem longe de produzir um conjunto de politicas de ações afirmativas que integre as comunidades negras. Em relação à mídia, o papel do negro em sua maioria é secundário, logicamente esporadicamente coloca um ou outro como protagonista.

Outro avanço na matéria de educação foi a instituição do PROUNI- Programa Universidade Para Todos do Governo Federal, através desse programa é concedido bolsas integrais ou totais, para estudantes carentes em instituições privadas. Quanto a esse vale ressaltar o entendimento do STF que declarou o Prouni constitucional:

EMENTA: AÇÕES DIRETAS DE INCONSTITUCIONALIDADE. MEDIDA PROVISÓRIA № 213/2004, CONVERTIDA NA LEI № 11.096/2005. PROGRAMA UNIVERSIDADE PARA TODOS - PROUNI.AÇÕES AFIRMATIVAS DO ESTADO. CUMPRIMENTO DO PRINCÍPIO CONSTITUCIONAL DA ISONOMIA. 1. A FENAFISP

...7.Toda a axiologia constitucional é tutelar de segmentos sociais brasileiros historicamente desfavorecidos, culturalmente sacrificados e até perseguidos, como, verbi gratia, o segmento dos negros e dos índios. Não por coincidência os que mais se alocam nos patamares patrimonialmente inferiores da pirâmide social. A desigualação em favor dos estudantes que cursaram o ensino médio em escolas públicas e os egressos de escolas privadas que hajam sido contemplados com bolsa integral não ofende a Constituição pátria, porquanto se trata de um descrímen que acompanha a toada da compensação de uma anterior e factual inferioridade ("ciclos cumulativos de desvantagens competitivas"). Com o que se homenageia a insuperável máxima aristotélica de que a verdadeira igualdade consiste em tratar igualmente os iguais e desigualmente os desiguais, máxima que Ruy Barbosa interpretou como o ideal de tratar igualmente os iguais, porém na medida em que se igualem; e tratar desigualmente os desiguais, também na medida em que se desigualem. 8. O PROUNI é um programa de ações afirmativas, que se operacionaliza mediante concessão de bolsas a alunos de baixa renda e diminuto grau de patrimonilização. Mas um programa concebido para operar por ato de adesão ou participação absolutamente voluntária, incompatível, portanto, com qualquer ideia de vinculação forçada. Inexistência de violação aos princípios constitucionais da autonomia universitária (art. 207) e da livre iniciativa (art. 170). ....Ação 
Direta de Inconstitucionalidade no 3.379 não conhecida. ADI's 3.314 e 3.330 julgadas improcedentes.

Outra questão atual é o da Lei de Cotas (no 12.711/2012) para estudantes nas universidades e seu decreto regulamentador ( $n$ - 7.824/2012). Conforme o texto, as universidades públicas federais e os institutos técnicos federais devem reservar, no mínimo, 50\% das vagas para estudantes que tenham cursado todo o ensino médio em escolas da rede pública, com distribuição proporcional das vagas entre negros, pardos e indígenas, tal regulamenta tem a intenção de nivelar certas desigualdades que ocorriam entre alunos vindos de escolas públicas e alunos vindos de escolas particulares. Entretanto, em relação a outros meios, casos ainda tem chamado a atenção do Judiciário, como por exemplo, um habeas corpus, julgado pelo STJ, que classificou discriminação e preconceito como racismo (HC 15.155).

\section{Ações afirmativas em favor da pessoa portadora de deficiência}

Sabe-se que pelo mundo e pela história foram cometidas várias barbáries contra os portadores de deficiência, Hitler é um destes, realizando experimentos nestas pessoas. No Brasil não se tem conhecimento que haveria algo parecido. O STJ vem contribuindo para o respeito às diferenças e garantia dos direitos de quem possuem algum tipo de deficiência. A integração do portador de deficiência na sociedade tem sido feita de vários âmbitos, como na educação, na saúde, no trabalho, a acessibilidade em locais públicos e privados e até mesmo em projetos de habitação. Em relação à educação, relata o autor Álvaro Ricardo de Souza Cruz:

...qualquer portador de deficiência tem direito a educação pública e gratuita, inclusive em sistema próprio de educação especial, adequada as suas necessidades, como se depreende do art. 2으, Inciso I, da lei no $7.853 / 89$, do artigo 58 da lei no 9.394/96 e do artigo do Decreto no 3.298/99. Entende-se por educação especial a modalidade oferecida preferencialmente na rede regular de ensino para o educando com necessidades especiais, constituindo-se num processo flexível, dinâmico e individual ligado às necessidades de cada portador de deficiência (2009, p. 215).

Acessibilidade é garantir que todas as pessoas tenham a capacidade de locomover-se a outras pessoas, que tenham acesso a atividades rotineiras sem elevada dificuldade, que tenham acesso a informações, a autonomia, liberdade e individualidade e um pleno acesso ao meio físico. Essa abordagem nos inúmeros foros busca respostas para os problemas vivenciados pela maioria dos municípios brasileiros. Deficiência conforme descrito pela ONU (Organizações das Nações Unidas) em 1975, refere-se a qualquer pessoa incapaz de assegurar por si mesma, total ou 
parcialmente, as necessidades de uma vida individual ou social normal, em decorrência de uma deficiência congênita ou não, em suas capacidades físicas, sensoriais ou mentais. Pode definir também que é toda perda ou anormalidade de uma estrutura ou função psicológica, fisiológica ou anatômica. Observando que esta pode ser permanente ou temporária.

Uma conquista realizada foi o status dado a Convenção Internacional sobre os Direitos das Pessoas com Deficiência e seu Protocolo Facultativo, assinados em Nova York, em 30 de março de 2007, promulgada no Brasil pelo Decreto № 6.949, de 25 de agosto de 2009, conforme o procedimento do §3으 do art. 5o da Constituição, que a estabeleceu como emenda Constitucional. Criando-se nela um parâmetro para o controle de constitucionalidade. Em que pese, apesar dos avanços desse tratado, e decisões do STF, verifica-se ainda uma lentidão para que se possa cumprir todas as medidas cabíveis e possíveis. Exemplo disse se dá com as poucas editorações de livros em brailes, arquitetura pública com elevadores e rampas, numero de professores com a qualificação necessária ao ensino e outros.

\section{CONCLUSÕES FINAIS}

A Constituição Federal de 1988 foi um grande passo a essa medidas, uma vez que consagrou em muitos dos seus artigos a igualdade material. Os tratados internacionais adotados pelo ordenamento jurídico brasileiro também são motivos de efetividade dos direitos humanos fundamentais. Entretanto ao que pese, as ações afirmativas terem ganhado notório interesse jurídico e politico nas ultimas décadas, pouco são os trabalhos efetivamente implantados, uma vez que são geradores de discussões, controvérsias e de ações de inconstitucionalidade, pelas classes que se dizem prejudicados com as medidas das ações afirmativas.

Como conclusão do presente trabalho, é indispensável que qualquer medida afirmativa deve ser primeiramente, bem estudada e segundo, bem legislada, para que esses direitos sejam efetivados as minorias. As ações afirmativas são sim, um meio de defesa e de inclusão social que devem ser garantido às minorias, uma vez que se tais meios beneficiam e podem igualar o tratamento de direitos e deveres de certo grupo inferiorizado, que em certo lapso de tempo encontra-se em desvantagens de direitos, porque não utiliza-las. Uma vez que os preconceitos são subjetivos é interessante além das medidas afirmativas, medidas de conscientização e medidas contra o preconceito. Importante salientar é que para que futuramente essas medidas e ações afirmativas não se tornem medidas desprovidas de efetivo meio de defesa, e passem a ser medidas que tragam benefícios exacerbados a somente um grupo, essas medidas devem ser 
temporárias, ou seja, devem agir por um determinado lapso de tempo. Em síntese, deve haver politicas públicas e privadas que resguardem o direito de todas as pessoas, principalmente os das minorias que de alguma forma tiveram seus direitos eliminados ou restritos.

\section{REFERÊNCIAS}

BAHIA, Sergio Rodrigues. Município e Acessibilidade. 1ed. Brasilia/DF:Editora.1998.

CRUZ, Álvaro Ricardo de Souza. O direito à diferença: as ações afirmativas como mecanismo de inclusão social de mulheres, negros, homossexuais e pessoas portadoras de deficiência. 3 ed. Belo Horizonte: Arraes, 2009.

FILHO, Manoel Gonçalves Ferreira Filho. Curso de Direito Constitucional. 38 ed. São Paulo: Saraiva, 2012.

NEVES, Gustavo Bregalda. Vade Mecum esquematizado de doutrina. 2 ed. Rideel Editora.2011.

OLIVEIRA, Adriano B. Koenigkam de; FERREIRA, Olavo A. Viana Alves. Como se preparar para o Exame de Ordem-Constitucional. 9 ed. Rio de Janeiro: Método, 2011.

PEDRO, Lenza. Direito Constitucional Esquematizado. 16 ed. São Paulo: Saraiva, 2012.

TORRES, Flávia Pinheiro Tavares. Guia de Acessibilidade Urbana/Prefeitura Municipal de Belo Horizonte e Conselho Regional de Engenharia, Arquitetura e Agronomia de Minas Gerais. 1 ed. Belo Horizonte:Editora. 2006.

TORRES, Flávia Pinheiro Tavares. Guia de Acessibilidade em Edificações.1 ed. Belo Horizonte:Editora. 2006.

Link:http://www.direitos.org.br/index.php?option=com content\&task=view\&id=1513\&ltemid=2 acessado em 12 de Maio de 2013.

Link:http://www.estadao.com.br/noticias/nacional,pastor-e-eleito-presidente-da-comissao-dedireitos-humanos-da-camara,1005618,0.htm acessado em 12 de Maio de 2013.

Link:http://www.stf.jus.br/portal/constituicao/artigobd.asp?item=\%2029 acessado em 12 de Maio de 2013.

Link:http://www.stj.jus.br/portal stj/publicacao/engine.Cwsp?tmp.area=44 acessado em 12 de Maio de 2013. 